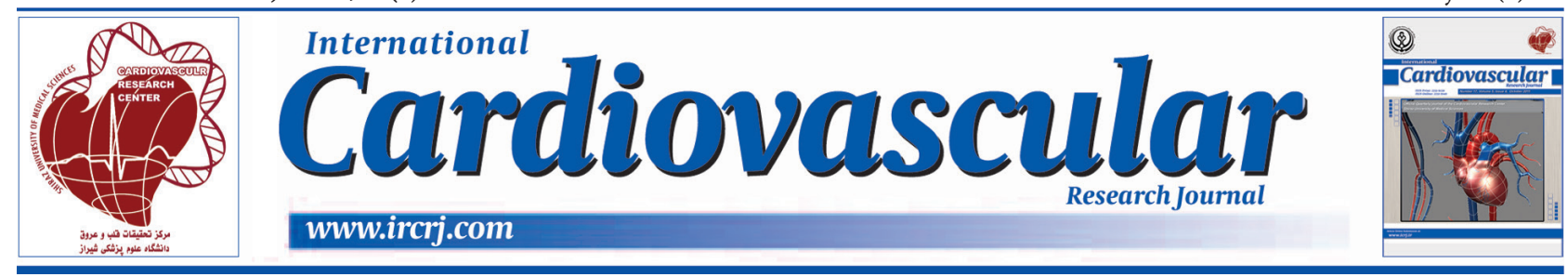

\title{
The Impact of Isolated Right Coronary Artery Angioplasty on Right Ventricular Functions in Patients with Unstable Angina Pectoris
}

\author{
Yavuzer Koza ${ }^{1, *}$ \\ ${ }^{1}$ Faculty of Medicine, Department of Cardiology Atatürk University, Erzurum, Turkey
}

\begin{abstract}
A R T I C L E I N F O
Article Type:

Article Commentary

Article History:

Received: 31 Jan 2015

Accepted: 17 Jun 2015

Keywords:

Echocardiography

Percutaneous Intervention

Right Ventricular Function

Implication for health policy/practice/research/medical education:

To date, the impact of the percutaneous intervention on left ventricular function has been widely studied, with little interest in the right ventricle. This article highlights the importance of the interdependence of the right and left ventricles and the role of percutaneous coronary intervention in the right ventricular function with regard to different lesion sites after isolated right coronary angioplasty.
\end{abstract}

Percutaneous Coronary Intervention (PCI) has been an integral part of management of coronary artery disease over the past three decades. PCI reduces mortality in ST-segment Elevation Myocardial Infarction (STEMI) and improves cardiovascular outcomes in non-STEMI and unstable angina $(1,2)$. However, the role of PCI in management of stable coronary artery disease is still debatable (3).

Although determined by interaction of a large number of factors, prognosis of patients with myocardial infarction is directly related to Left Ventricular (LV) function and size (4). In clinical practice, the right ventricle has remained a forgotten chamber behind the left ventricle. Likewise, most studies have evaluated the prognostic importance of LV function with little interest in the right ventricle. However, involvement of the right ventricle was significantly associated with increased mortality in patients with acute STEMI treated with primary PCI (5).

The study by Nikdoust et al. (6) in a recent issue of the

${ }^{*}$ Corresponding author: Yavuzer Koza, Atatürk University, Faculty of Medicine, Department of Cardiology, Erzurum, Turkey Tel: +90-4422318503,

E-mail:yavuzerkoza@hotmail.com
International Cardiovascular Research Journal highlights a significant improvement in Right Ventricular (RV) function, but not LV function, after Right Coronary Artery (RCA) PCI in patients with unstable angina. Echocardiographic measurements were performed in a total of 30 subjects prior to elective PCI. Two months after PCI, echocardiography was repeated and the results were compared to baseline. According to the findings, RV systolic and diastolic functional parameters were significantly improved, but there was no significant correlation between these parameters and LV function. Thus, the authors suggested that revascularization of the RCA might be beneficial for patients suffering from RV failure due to ischemia.

The significant improvement in RV, but not LV, function, after right coronary PCI in a relatively small population is interesting. In agreement with this study, previous studies also reported significant improvements in RV function after PCI. However, these studies mainly included STEMI patients with different locations (5). In a study on 133 patients with inferior infarction without concomitant RV infarction who underwent primary PCI, only regional RV 
diastolic dysfunction was observed, whereas alteration of global RV function was more pronounced in patients with anterior wall infarction (7). This study also provided an additional information with the inclusion of unstable angina patients who were referred for isolated RCA PCI.

The right ventricle is different from the left ventricle with respect to many anatomic and physiologic aspects, but they are not independent from each other. The size, shape, and compliance of one ventricle affect the hemodynamic properties of the other, which is called ventricular interdependence (8). As a part of the right ventricle, the interventricular septum is affected more by the left ventricle than by the right ventricle, except in advanced RV dysfunction or severe pulmonary hypertension. Furthermore, inclusion of the interventricular septum in assessment of global RV function is challenging (9).

In $85 \%$ of world's population, two-thirds of the right ventricle is supplied by the RCA, whereby RCA gives rise to the posterior descending artery, posterolateral artery, and atrioventricular nodal artery; i.e., right dominant. The inferior wall of the right ventricle is the most susceptible segment to ischemia, while the infundibulum and anterior wall are the most resistant. The elaborate collateral circulation of the right ventricle can protect it against ischemia in case of proximal RCA occlusion (8). Because the severity of RV dysfunction depends on the location of RCA occlusion, information about the lesion sites, collateral vessels, and dominancy or codominancy would be useful.

RV systolic and diastolic functions can be measured by various echocardiographic parameters, including Right Ventricular Fractional Area Change (RVFAC), Tricuspid Annular Plan Systolic Excursion (TAPSE), Tissue Doppler Imaging (TDI), and Myocardial Performance Index (MPI). All these parameters have many inherent limitations. For instance, RVFAC is experience-dependent with poor reproducibility. In addition, TAPSE may not fully reflect RV contractility as it does not take segmental RV function into account (10). Previous studies have reported that subtle but clinically relevant decreases in ventricular function can be detected using strain $(8,11)$. Chang et al. (12) also disclosed that in comparison to other traditional echocardiographic parameters of RV assessment, RV free wall longitudinal strain was better for detection of chronic RCA disease.

In contrast to this study, Moller et al. (13) investigated the serial changes of RV function after acute myocardial infarction and found that RV MPI was significantly correlated to LV MPI and this was presumed to be related to ventricular interdependence as mentioned above. In the GISSI-3 Echo substudy, TAPSE was significantly associated with Left Ventricular Ejection Fraction (LVEF) and as LVEF recovered over time, RV function improvement was also observed (14).

In conclusion, it is not clear whether recognition of $\mathrm{RV}$ dysfunction in patients with unstable angina will alter our management strategies, such as PCI, and/or medical treatment. Nonetheless, more precise characterization of $\mathrm{RV}$ function is warranted to improve our understanding of pathophysiological changes in the right ventricle after reperfusion of a single vessel disease with involvement of the RCA.

\section{Acknowledgements}

There is no acknowlwdgement.

\section{Authors' Contribution}

Yavuzer Koza developed the original idea and the protocol, abstracted and analyzed the data, and wrote the manuscript.

\section{Financial disclosure}

There is no financial interest related to the material in the manuscript.

\section{Funding/Support}

There is no funding/support.

\section{References}

1. Bonnefoy E, Lapostolle F, Leizorovicz A, Steg G, McFadden EP, Dubien PY, et al. Primary angioplasty versus prehospital fibrinolysis in acute myocardial infarction: a randomised study. Lancet. 2002;360(9336):825-9.

2. Fox KA, Poole-Wilson PA, Henderson RA, Clayton TC, Chamberlain DA, Shaw TR, et al. Interventional versus conservative treatment for patients with unstable angina or non-ST-elevation myocardial infarction: the British Heart Foundation RITA 3 randomised trial. Randomized Intervention Trial of unstable Angina. Lancet. 2002;360(9335):743-51.

3. Pursnani S, Korley F, Gopaul R, Kanade P, Chandra N, Shaw RE, et al. Percutaneous coronary intervention versus optimal medical therapy in stable coronary artery disease: a systematic review and meta-analysis of randomized clinical trials. Circ Cardiovasc Interv. 2012;5(4):476-90

4. St John Sutton M, Pfeffer MA, Plappert T, Rouleau JL, Moye LA, Dagenais GR, et al. Quantitative two-dimensional echocardiographic measurements are major predictors of adverse cardiovascular events after acute myocardial infarction. The protective effects of captopril. Circulation. 1994;89(1):68-75.

5. Antoni ML, Scherptong RW, Atary JZ, Boersma E, Holman ER, van der Wall EE, et al. Prognostic value of right ventricular function in patients after acute myocardial infarction treated with primary percutaneous coronary intervention. Circ Cardiovasc Imaging. 2010;3(3):264-71.

6. Nikdoust F, Tabatabaei SA, Shafiee A, Mostafavi A, Mohamadi M, Mohammadi S. The effect of elective percutaneous coronary intervention of the right coronary artery on right ventricular function. Int Cardiovasc Res J. 2014;8(4):148-51.

7. Hsu SY, Lin JF, Chang SH. Right ventricular function in patients with different infarction sites after a first acute myocardial infarction. Am J Med Sci. 2011;342(6):474-9.

8. Haddad F, Hunt SA, Rosenthal DN, Murphy DJ. Right ventricular function in cardiovascular disease, part I: Anatomy, physiology, aging, and functional assessment of the right ventricle. Circulation. 2008;117(11):1436-48.

9. Leung DY, Ng AC. Emerging clinical role of strain imaging in echocardiography. Heart Lung Circ. 2010;19(3):161-74.

10. Rudski LG, Lai WW, Afilalo J, Hua L, Handschumacher MD, Chandrasekaran K, et al. Guidelines for the echocardiographic assessment of the right heart in adults: a report from the American Society of Echocardiography endorsed by the European Association of Echocardiography, a registered branch of the European Society of Cardiology, and the Canadian Society of Echocardiography. J Am Soc Echocardiogr. 2010;23(7):685-713; quiz 86-8.

11. Giusca S, Dambrauskaite V, Scheurwegs C, D’Hooge J, Claus P, Herbots L, et al. Deformation imaging describes right ventricular function better than longitudinal displacement of the tricuspid ring. Heart. 2010;96(4):281-8.

12. Chang WT, Tsai WC, Liu YW, Lee CH, Liu PY, Chen JY, et al. Changes in right ventricular free wall strain in patients with coronary artery disease involving the right coronary artery. $J \mathrm{Am}$ Soc Echocardiogr. 2014;27(3):230-8.

13. Moller JE, Sondergaard E, Poulsen SH, Appleton CP, Egstrup K. Serial Doppler echocardiographic assessment of left and right 
ventricular performance after a first myocardial infarction. $J A m$ Soc Echocardiogr. 2001;14(4):249-55.

14. Popescu BA, Antonini-Canterin F, Temporelli PL, Giannuzzi P, Bosimini E, Gentile F, et al. Right ventricular functional recovery after acute myocardial infarction: relation with left ventricular function and interventricular septum motion. GISSI-3 echo substudy. Heart. 2005;91(4):484-8 